\title{
Research on Logistics Cost Accounting Staff Personnel Cultivation Standards
}

\author{
Xiuli TAN \& Bayi GUAN \& Zhanli SHANG \\ Yantai Nanshan University, Yantai, Shandong, China
}

\begin{abstract}
With the continuous development of the Internet finance, the personnel cultivation standards are being spawned intensive development by logistics ecology and financial ecology. The competition of modern logistics is embodied in three characteristics: channels, cost and service. The role of a cost accounting staff in the ecological chain of the logistics is attracted widespread attention. What is specific logistics cost accounting staff consistent with personnel cultivation standards? In this paper, the professional competence of staff personnel cultivation standards of a cost accounting staff is discussed by using the method of post ability analysis and example application, and then come to conclusion that a logistics cost accounting staff should have three competency standards, the channels to explore, cost accounting, service care about.
\end{abstract}

KEYWORD: Logistics; cost accounting staff; cultivation; standards; research

With the continuous development of the Internet finance, logistics industry is also gradually changing from traditional logistics to modern logistics transformation, mainly embodied in the logistics personnel specialized and intensive transformation which more than one person engaged in multiple posts before gradually to one person engaged in multiple posts in recently, which put forward many requirements for post standard of the logistics personnel. This paper mainly studies three basic competency standards of the logistics cost accounting staff which are the channels of analysis and maintenance, cost accounting, service.

\section{ANALYSIS AND MAINTENANCE OF CHANNEL CAPACITY OF LOGISTICS COST ACCOUNTING STAFF}

As a logistics costs accounting staff, firstly, he should understand the three channels of logistics transportation and distribution: sea, land or air transport. Secondly, he should comprehend that the geographical location's distribution, the collocation of the means of transport and flight and transportation cost accounting in the three transport channels. Third, for channel maintenance, he should pay attention to transport time, cost of tie-in and the maintenance and explore of customers in the three transport channels. Concrete analysis is as follows.

\subsection{Analysis ability of transport channel of the land, sea and air}

As a logistics costs accounting staff, he should have a basic cognitive framework in land, sea or air transport.

\subsubsection{Sea transport}

Sea transport has the largest channel capacity and its freight cost is low but freight time is long. With the requirements of the time limit, the analysis of time in the arrival of the goods is needed. As a logistics cost accounting staff accounting cost of the sea transport channel: first of all, he should be familiar with pier, routes, flights, shifts, sailing and arrival time of this unit nearby logistics distribution center; Second, he should be familiar with the calculation of freight; Third, he can estimate the number of goods transfer and reduce the cost loss in the transport in order to reduce the cost of transport and improve the efficiency of it.

\subsubsection{Land transport}

Land transport is the most basic logistics transport channel which is convenient and flexible of transportation, fewer transit, alternative diversified transportation, elastic of the freight, facilitating decision making of cost accounting and the options of transportation tools according to the supply of goods and transportation distance. As a logistics cost accounting staff when accounting the cost of road 
transport channels: firstly, he should be familiar with the divisions, the time and receiving way of the passenger distribution, motor freight or rail transport; Secondly, he should be familiar with the freight and tariff calculation's basis of all kinds of logistics transport; Thirdly, according to the condition of the batch size and the delegate distribution price he can choose and arrange suitable logistics tools.

\subsubsection{Air transport}

In three transport channels of land, sea or air, air freight is the most efficient which the freight is relatively high, suitable for cost-effective logistics products distribution transport. As a logistics cost accounting staff, when he accounts the air channel cost: first of all, he should be familiar with the flights and flights absences and arrival time nearby the logistics center. Secondly, he should be familiar with the freight and rate calculation rule of air freight because air freight's security facilities are the most strict and requirements for supply goods are relatively higher; Thirdly, he should timely grasp weather situation, grasp air freight's departure and arrival on time and possible delays, avoid the cost risk caused by the default.

\subsection{Maintenance abilities of transport channels and customers' source of the land, sea or air}

The inclinations of the logistics industry are the transport channels' and customers' source. If there are no channels, the logistics industry just like people clogged arteries lead to paralysis, it will be unlikely to a good supply of goods and freight to become a reality; If there are no customers, it will lost logistics transport objects and nothing can flow. Therefore, the maintenance of transportation channels and customers' source are very important.

\subsubsection{Logistics channel maintenance}

Channel maintenance is in order to guarantee the unimpeded, convenient and efficient channel. In the logistics industry, Land, sea or air freight all need to be efficient and smooth channels. As a logistics cost accounting staff, he needs to analyze personnel structure, communication frequency and cost expenditure of maintenance costs of the three channels, make a transport channel cost budget, ensure that the units and the brother unit cooperation and enhance the competitiveness of the enterprise in the logistics industry.

\subsubsection{Logistics customers' source maintenance}

The logistics industry tends to be the third party in the role to ensure that the interests of the entrusting party shall not be subject to damage and the ones of the receiving party shall not be affected. In such cases, it embodies the principle of customer first and maintenance of customers' source in pursuit of its own profit maximization. In current logistics, Because of blind pursuit of their own interests at the expense of the interests of customers, so the logistics enterprise loses their customers for which inefficient of arrival of the goods and damage of the goods in some degree. As a logistics cost accounting staff, in logistics customers' source maintenance, he should make the necessary goods packaging, distribution channels, tools selection and customer requirement analysis as far as possible to ensure timely delivery and cargo intact. To the damage due to his own reason, he would compensate customer's loss in time in order to improve the reputation and competitiveness, so the customers' sources will retain.

\section{THE ABILITY OF COST ACCOUNTING OF LOGISTICS COST ACCOUNTING STAFF}

The lifeline of enterprise survival is profit. As modern high-speed development logistics enterprises, the profits and losses are inevitable; therefore it requires logistics cost accounting staff must have the ability of cost accounting. The nature of the cost accounting based on cost can be divided into Period costs accounting and process cost accounting.

\subsection{Period costs accounting}

There are seven matters when someone opens the door: firewood, rice, oil, salt, sauce, vinegar and tea. Every day a family, whatever you do or not do, must face to open the door seven matters' expenses, which are period cost. A sound logistics enterprises, no matter how well your business, must have certain expenses, since these costs cannot be directly contributed to the subject matters of the cost of logistics, so called period costs.. Specific ones include: operating expenses, management fees and finance charges. As a logistics cost accounting staff, he needs to master the ability of period costs accounting, to divide precisely which ones are in the period of cost accounting and which ones are in the logistics cost accounting to improve the enterprise's operating revenues, reduce the period cost, carry on the reasonable configuration and provide decision basis and reference.

\subsection{The logistics cost calculation ability}

Logistics cost accounting ability mainly refers to the allocation accounting ability of storage cost and processing and packaging cost of the subject matter. Usually, the standard of logistics distribution 
enterprise storage warehouse, which there are a number of goods warehouses in order to guarantee the quality of the goods unchanged, some are required steam supply in a certain temperature, some are required water supply under certain humidity, etc. The cost of the auxiliary workshop needs to be allocated to the logistics cost of the subject matter, As a logistics cost accounting staff, he needs to have the capacity to cost accounting. Auxiliary cost of Kowloon Logistics Company illustrate that a logistics cost accounting staff should have cost accounting ability standards by algebra method and case study under the cost distribution.

Case study: Kowloon logistics company have tow auxiliary workshop, boiler shop and overhaul shop, which provide stream heat and repairing vehicles. In November, the boiler shop and overhaul shop total cost is $287300 \mathrm{RMB}$ and 123000 RMB respectively. (See the chart below)

Table1.The cost summary of auxiliary workshop providing service.

\begin{tabular}{|l|l|l|l|}
\hline \multicolumn{2}{|l|}{ Beneficiaries } & $\begin{array}{l}\text { Steam } \\
\text { tons }\end{array}$ & $\begin{array}{l}\text { Maintenance } \\
\text { hour }\end{array}$ \\
\hline $\begin{array}{l}\text { Auxiliary } \\
\text { production } \\
\text { workshop }\end{array}$ & $\begin{array}{l}\text { Boiler } \\
\text { workshop }\end{array}$ & & 2000 \\
\cline { 2 - 4 } & Overhaul shop & 4000 & \\
\hline Basic production workshop & 95000 & 25000 \\
\hline The administrative departments & 35000 & 5000 \\
\hline Total & 134000 & 32000 \\
\hline
\end{tabular}

According to the above data, a logistics cost accounting staff calculates that the auxiliary production department shall bear the expenses using algebraic allocation method.

The role of this application mainly checks that a logistics cost accounting staff should possess basic math knowledge to solve the basic problem of cost accounting by using multivariate equations and master the precise calculation method to guarantee the accuracy of cost allocation.

Case of solution is as follows:

Set $\mathrm{x}$ for the cost of per ton steam of boiler workshop, set $y$ for repair costs of per hour of overhaul shop, then set up simultaneous equations as follows:

$$
\left\{\begin{array}{l}
287300+2000 y=134000 x \\
23000+4000 x=32000 y
\end{array}\right.
$$

Solution: $\mathrm{x}=2.2055(\mathrm{RMB} / \mathrm{t})$

$$
\mathrm{y}=4.1185(\mathrm{RMB} / \mathrm{h})
$$

The cost of boiler workshop is:

$$
2.2055 * 134=295,537,134(\mathrm{RMB})
$$

The cost of overhaul shop is:

$$
4.1185 * 32000=131,792(\mathrm{RMB})
$$

\section{LOGISTICS SERVICE CAPABILITY OF COST ACCOUNTING STAFF}

With the rapid development of logistics industry, the competition is also growing. In addition to the channels and cost advantage, the service determines the logistics enterprise survival space and customer competition ability in some extent. A cost accounting staff should have interactive communication ability, logistics culture display ability, SWOT analysis ability in logistics services, in order to get hold of the customer real needs and potential demand and psychological guidance.

\subsection{Communication ability}

Communication is to understand each other and let customer know services that the logistics enterprise can provide. Interaction means that staff and customer exchange ideas by communication platform, and get brain storming and the best solution. A logistics cost accounting staff is directly contact with customers, to get customer needs and discuss the transportation channel and cost. In the cost range, he conducts business and eventually helps the manager to make the decision of accepting the order or not. Therefore, a logistics cost accounting staff must have good communication capabilities, so that both sides can open up for business cooperation.

\subsection{Logistics culture display capability}

Enterprise culture often represents the value orientation and positioning of an enterprise and can produce peep one spot and see whole picture effect. Each and all logistics enterprises should fully display its logistics culture which is also a kind of service. For example, the following shows in the logistics cost accounting staff office should at least: the first is Chinese traffic geographic transportation map, including armed three transport channels, the aim is to channel analysis and logistics freight accounting; the second is the map of the world and the surrounding transportation lines depict; the third is domestic, international transportation schedule and arriving and leaving timetable, the fourth is the tariff and contact of the enterprise, because it is a common concern to the customers; the fifth is the development plan and the enterprise service philosophy. With the basic show, any customer coming to the company, can see the logistics service and the overall rates of enterprises clearly, saving a lot of explanatory items, significantly improving 
work efficiency. Although logistics culture display is trivial, but needs a logistics cost accounting staff carefully arrange hence fully display the enterprise logistics culture.

\subsection{SWOT analysis ability}

SWOT analysis ability is mastering the strength weakness opportunity and threats of the enterprise faced currently and to analyze how to take advantage of the strength, how to make up for lack and how to use opportunities avoiding risks. Every enterprise has its own strength, weakness, opportunities and threats, the cost accounting staff must have abilities to analyzing the circumstances and taking action with thinking about both sides and so obtain the both sides satisfied.

\section{CONCLUSION}

Development of logistics enterprises spawned demand for the talent. The logistics cost accounting staff personnel cultivation standard is coming in which a qualified member of the logistics cost accounting who is qualified personnel should have the ability to analyze and maintain logistics channels, costing capabilities, logistics service capability.
This paper is the research result of Research on Construction of Characteristic Profession and disciplines of Private University based on regional development (2013GG203) Shandong Province Education Science "Twelve Five" planning project.

This paper is the research result of Social Science and Planning Research Project of Yantai City "Supply Chain's Financial Ecological Environment Optimizing Research in Yantai "key topics: (Project Number: ytsk2014-028)

This paper is the research result of Young Teachers Fund Project of Yantai Nanshan University "Financial Model and Risk Management Based on Logistics of Regional Economic Development" (Item Number: 201408)

This paper is the research result of Young Teacher Education Research Project of Shandong Province: Universities Logistics Application Personnel Skills Standards under the new situation in 2015(Project number: 15SDJ165).

\section{REFERENCES}

[1] Huang Z.D., Zhang S.Y. 2013. Modern logistics management. Shanghai. Fu Dan University Press

[2] Jiang X.H., Xiang Y.C. 2011.Cost accounting tutorial (fourth edition).Beijing. Higher Education Press 